\title{
Correction to: The Invested in Diabetes Study Protocol: a cluster randomized pragmatic trial comparing standardized and patient-driven diabetes shared medical appointments
}

\author{
Bethany M. Kwan ${ }^{1 *}$, L. Miriam Dickinson ${ }^{1}$, Russell E. Glasgow ${ }^{1,2}$, Martha Sajatovic ${ }^{3}$, Mark Gritz ${ }^{1}$, \\ Jodi Summers Holtrop ${ }^{1}$, Don E. Nease $\mathrm{Jr}^{1}$, Natalie Ritchie ${ }^{1,4}$, Andrea Nederveld ${ }^{1}$, Dennis Gurfinkel ${ }^{1}$ and \\ Jeanette A. Waxmonsky ${ }^{1,2}$
}

\section{Correction to: Trials \\ https://doi.org/10.1186/s13063-019-3938-7}

After publication of our article [1] the authors have notified us that the title for Figure 1 was incorrectly captioned in addition it was noticed that the Interventions section contained two errors.

- Originally published Figure 1 title: SPIRIT Figure for Invested in Diabetes project timeline

- Correct Figure 1 title: Invested in Diabetes study conceptual model.

The error: Patients step out of group for brief [510]individual visits with a provider with prescribing privileges, who provides medication management, orders and referrals, and patient-specific medical advice, i.e. curriculum, dose of intervention, frequency of sessions, visits with medical providers, and group size are consistent across study arms, and are thus not variables in the study.

Should instead read: Patients step out of group for brief (5-10 minutes) individual visits with a provider with prescribing privileges, who provides medication management, orders and referrals, and patient-specific medical advice. Curriculum, dose of intervention, frequency of sessions, visits with medical providers, and group size are consistent across study arms, and are thus not variables in the study.

The original article has been corrected.

\section{Author details \\ 'University of Colorado School of Medicine, 13199 E Montview Blvd Ste 210, Aurora, CO 80045, USA. ${ }^{2}$ VA Eastern Colorado QUERI and Geriatric Research Centers, 1055 Clermont St, Denver, CO 80220, USA. ${ }^{3}$ Case Western Reserve University, 10900 Euclid Ave, Cleveland, OH 44106, USA. ${ }^{4}$ Denver Health and Hospital Authority, 777 Bannock St, Denver, CO 80204, USA.}

Published online: 18 February 2020

\section{Reference}

1. Kwan, et al. The Invested in Diabetes Study Protocol: a cluster randomized pragmatic trial comparing standardized and patient-driven diabetes shared medical appointments. Trials. 2020;21:65. https://doi.org/10.1186/s13063019-3938-7.

The original article can be found online at https://doi.org/10.1186/s13063019-3938-7

* Correspondence: bethany.kwan@cuanschutz.edu

'University of Colorado School of Medicine, 13199 E Montview Blvd Ste 210,

Aurora, CO 80045, USA

Full list of author information is available at the end of the article

(c) The Author(s). 2020 Open Access This article is distributed under the terms of the Creative Commons Attribution 4.0 International License (http://creativecommons.org/licenses/by/4.0/), which permits unrestricted use, distribution, and reproduction in any medium, provided you give appropriate credit to the original author(s) and the source, provide a link to the Creative Commons license, and indicate if changes were made. The Creative Commons Public Domain Dedication waiver (http://creativecommons.org/publicdomain/zero/1.0/) applies to the data made available in this article, unless otherwise stated. 